\title{
Do Emotions Matter? The Relationship Between Math Anxiety, Trait Anxiety, and Problem Solving Ability
}

\author{
Matúš Grežo, Ivan Sarmány-Schuller \\ Institute of Experimental Psychology, Centre of Social and Psychological Sciences, \\ Slovak Academy of Sciences
}

\begin{abstract}
In this study, we examined the relations between math anxiety, trait anxiety, and one's perceived problem solving ability on a sample of 128 university students. Participants completed a revised version of the Fennema-Sherman Mathematics Anxiety Scale, The State-Trait Anxiety Inventory, and the shortened version of Problem Solving Inventory. The results showed a moderate negative relationship between trait anxiety and individual's perceptions regarding his/ her problem solving abilities. More specifically, we found that trait anxiety was negatively related to perceived self-confidence to solve problems and ability to self-control the emotions and behavior associated with the process of problem solving. However, it was not significantly associated with the tendency to avoid/approach problems. Finally, the perceived problem solving ability did not mediate the relationship between trait anxiety and math anxiety. Besides examining the effect of particular personality traits, we highlight the importance of further investigating the role of age and environmental and contextual factors, as well as the frequency and intensity of threatening math situations an individual faces in his/her life in regard to math anxiety.
\end{abstract}

Key words: problem solving, trait anxiety, math anxiety

\section{Introduction}

During studies, an individual has to face many stressful situations that are often associated with experiencing anxiety (Dowker, Sarkar, \& Looi, 2016). Besides test anxiety (see Zeidner,

\section{Acknowledgements:}

The paper was presented at the $38^{\text {th }}$ STAR Conference: Stress, Anxiety, and Resilience: Challenges of the $21^{\text {st }}$ Century, $5^{\text {th }}-7^{\text {th }}$ July, 2017, Hong Kong.

This work was supported by the grant agency VEGA no. $2 / 0116 / 15$

Correspondence concerning this article should be addressed to Matúš Grežo, Institute of Experimental Psychology, Centre of Social and Psychological Sciences, Slovak Academy of Sciences, Dúbravská cesta 9, 84104 Bratislava, Slovak Republic. E-mail: matus.grezo@savba.sk

Received May 31, 2018
1988), there are some specific academic domains/subjects that trigger greater anxiety than others. Some studies show that one such domain is mathematics (Punaro \& Reeve, 2012; Dowker, 2005; Wigfield \& Meece, 1988). As Dowker, Sarkar, and Looi (2016) state, math anxiety can have a serious negative effect on mathematical learning and performance, because it causes avoidance of mathematics and overloads the working memory in mathematical tasks. Moreover, people exhibit math anxiety not only in the academic context, but also in everyday life when confronted with mathematical problem solving or situations where numerals have to be manipulated (Richardson \& Suinn, 1972).

Although math anxiety and trait anxiety are distinct constructs, research shows that they are positively related (Hembree, 1990). Moreover, it has been shown that math anxiety affects performance in various cognitive tasks (Ashcraft, Kirk, \& Hopko, 1998; Ashcraft \& Rid- 
ley, 2005). A significant portion of research on math anxiety has focused on investigating its effect on problem solving. However, the majority of these studies examined only the problem solving performance on mathematical tasks (see Ashcraft, 1992 for a review). In these studies, math anxiety is often considered an independent factor affecting performance in mathematical problem tasks. However, Ashcraft and Rudig (2012) pointed out an important issue about research on math anxiety, and that is the problem of causality. They stated that we often do not know whether it is math anxiety that affects one's behavior, or it is the lower ability in mathematics that causes bad performance and subsequently triggers math anxiety. Considering this, we could assume that not just math anxiety affects problem solving, but also the individual's lower levels of problem solving abilities can lead to lower performance in math and be the antecedent of math anxiety. However, very little is known about the impact of general problem solving ability or problem solving style on the occurrence of math anxiety. This assumption can be supported by several studies, which indicated that problem solving ability was a significant predictor of psychological adjustment, or the ability to cope with stress and anxiety (see Heppner, Witty, \& Dixon, 2004 for a review). Despite this assumption, based on the analysis of current relevant literature, the investigation of the relationship between an individual's general problem solving ability and math anxiety is not thoroughly researched.

In this study, we aim to investigate links between math anxiety, trait anxiety, and perceived problem solving ability. Since math anxiety is often associated with math avoidance (Turner et al., 2002) and also low self-confidence in mathematics (Hembree, 1990), our aim is to explore these factors as facets of general problem solving ability and investigate how they are associated with both math anxiety and trait anxiety.

\section{Theoretical Background}

The Definition and Consequences of Math Anxiety

Math anxiety can be defined as "a feeling of tension, apprehension, or fear that interferes with math performance" (Ashcraft, 2002; p. 181). Similarly, Fennema and Sherman (1976; p. 326) define math anxiety as "feelings of anxiety, dread, nervousness, and associated bodily symptoms related to doing mathematics". In their definition, Richardson and Suinn (1972), and Buckley and Ribordy (1982) highlighted that these negative feelings can be experienced not just during math courses or math testing, but also in many common everyday situations like reading a cash register receipt after the purchase or buying a math book. Similar to other types of anxiety, research on math anxiety shows that it impacts the individual's affect, behavior, cognition, and desires (the ABCDs of personality, see Wilt, Oehlberg, \& Revelle, 2011).

\section{Math Anxiety and Affect}

The affective aspect of math anxiety is already stated in its definitions. Math anxiety is characterized as experiencing negative emotions of fear, tension, or nervousness. Considering standard diagnostic criteria (e.g., anxiety reactions, signs of elevated cognitive and physiological arousal, a learned situation- and stimulus-specific reaction, etc.), Faust (1992) claims that math anxiety could be perceived as a genuine phobia. Negative feelings are mostly triggered by situations that are perceived as threatening, such as new unfamiliar problems, overly complex problems, or situations where individuals perceive negative expectations (Onwuegbuzie \& Wilson, 2003). Moreover, negative feelings are experienced also on a physiological level (Fennema \& Sherman, 1976; 
Faust, 1992). Pletzer et al. (2010) measured individuals' changes in cortisol level (stress hormone) and also math anxiety during statistics exams. They found that the majority of participants showed an increase in cortisol before the exams, and a decrease after the exams. Dogan (2010) discussed another factor that is tightly connected to individual's affectivity and that is self-confidence in relation to math anxiety. He claims that an individual's doubts about his own abilities not only limit him/her in acquiring the knowledge of the subject, but also lead to reluctance and discouragement from pursuing studies or jobs that require mathematical knowledge. The relation between self-confidence and math anxiety was also discussed by Ashcraft (2002), who stated that this relation shows to be strongly negative, ranging from -.47 to -.82 . Finally, Hembree (1990) in his meta-analysis also found a strong negative relationship between math anxiety and self-confidence about math.

Previous studies showed that math anxiety is linked to several other forms of anxiety. Betz (1978), in her seminal work, found math anxiety to be positively associated with test anxiety and also trait anxiety. Dew, Galasi, and Galasi (1983) and Morsanyi, Busdraghi, and Primi (2014) found a positive relationship between math anxiety and test anxiety as well. Similarly, results of the meta-analysis of Hembree (1990) showed that math anxiety was associated with test anxiety, but it also correlated with state and trait anxiety, as well as general anxiety. All these relationships showed to be low-to-moderate, while the strongest association was reported between math and test anxiety. Although relatively high associations of math anxiety with other anxiety constructs were reported in previous studies, Dowker, Sarkar, and Looi (2016) highlight that math anxiety cannot be reduced only to test or general anxiety, because different measures of math anxiety correlate more strongly with each other than with test anxiety or general anxiety measures.

\section{Math Anxiety and Cognition}

Besides the affective dimension, math anxiety also affects individual's cognitions. Math anxiety was showed to be strongly related to mathematics achievement (Richardson \& Suinn, 1972; Wigfield \& Meece, 1988; Hembree, 1990; Ma, 1999; Zakaria \& Nordin, 2008). The negative effect of math anxiety on math achievement was also reported in three meta-analyses (Hembree, 1990; Ma, 1999; Sad, Kis, Demir, \& Özer, 2016). Moreover, this effect was reported across several age populations (Ma, 1999).

A significant number of studies on math anxiety investigated its effect on mathematical problem solving, or performance in math-related tasks (Maloney \& Beilock, 2012). Yeo (2005) investigated the role of math anxiety in nonroutine mathematical problem solving. He found a significant weak negative relationship between math anxiety and performance in these tasks. A very similar relationship was reported by Karasel, Ayda, \& Tezer (2010). Novak and Tassel (2017) investigated the effect of math anxiety, working memory, spatial ability, and math attitudes on performance in geometry, word, and non-word problem solving. They found that the first three factors explained $62 \%$ of the variance in individuals' math performance, while math anxiety showed to be the highest negative predictor. In order to explain the negative association between math anxiety and performance in math-related tasks, several studies investigated the role of working memory in this relationship (Hitch, 1978; Fürst \& Hitch, 2000; Ganley \& Vasilyeva, 2014; Mattarella-Micke et al., 2011).

In a recent study of Ramirez et al. (2016), it was found that math anxiety was negatively related to the use of more advanced problem solving strategies, which in turn were related to an individual's math achievement. Moreover, Ramirez et al. (2016) found that this relationship 
was the strongest mostly among individuals with the highest working memory capacity. According to Ashcraft (2002), negative feelings in highly math anxious individuals distract their attention from the task and overload their working memory. Since arithmetic and other mathrelated tasks are strongly affected by the working memory capacity, the disruption of working memory by math anxiety seriously impacts math performance. For instance, Ashcraft and Kirk (2001) found that highly math anxious individuals had reduced working memory capacity, which lead to the increase in reaction time and also to errors in math-related tasks.

\section{Math Anxiety and Behavior}

Both affective and cognitive consequences are tightly connected to one's behavior. In the literature, the mostly discussed behavioral consequence of math anxiety is math avoidance (Betz, 1978; Ashcraft, Kirk, \& Hopko, 1998). As Ashcraft and Krause (2007) stated, math anxiety leads students to avoid taking mathematics classes, but also to avoid situations in which mathematics may be necessary. This tendency does not concern only avoiding math courses, or math testing, but also the reluctance to follow math-related studies and careers (Dogan, 2010; Ashcraft \& Moore, 2009). Although from the perspective of others, math anxious individuals look like they are unmotivated, Covington (1992) states that, on the contrary, anxious individuals are actually very highly motivated, but this motivation occurs in order to avoid failure and not to learn mathematics. Even when math anxious individuals are in a situation requiring mathematical performance, they have tendencies to use the so called "local avoidance" strategy. Ashcraft (2002) describes this phenomenon as a certain tradeoff between speed and accuracy. With his colleagues, he found that highly-anxious individuals responded very rapidly to mathematical problems, sometimes as rapidly as individuals with low anxiety, but this speed was at the cost of accuracy. They stated that highly anxious individuals sacrifice accuracy (having more errors) in order to minimize the time and involvement in mathematics tasks.

\section{Problem Solving Ability}

We highlighted that math anxiety showed to be strongly related to avoidance behavior (e.g., Hembree, 1990). However, very little is known about whether this avoidant behavior is caused by math anxiety itself, or if it is driven by more general problem solving strategies. It is a wellresearched finding that individuals vary in the degree to which they tend to approach or avoid problems and these tendencies are systematic (approach/avoidance coping strategies - see Roth \& Cohen, 1986). Approach/avoidance strategies were thoroughly researched as a partial dimension of one's problem solving appraisal by Heppner and his colleagues (see Heppner, Witty, \& Dixon, 2004 for review). The problem solving appraisal is defined as one's perception of his/her personal problem solving style and the identification of his abilities and skills to solve problems (D'Zurilla \& Nezu, 2007). This construct consists of three dimensions: problem solving confidence (PSC), approachavoidance style (AAS), and personal control (PC). The first dimension (PSC) is defined as a degree of certainty and self-assurance when facing a wide range of problems. It describes one's tendency to trust his/her own ability to solve problems. The second dimension (AAS) is describing a tendency to approach or avoid problems, and the third dimension (PC) is describing one's ability to control his/her emotions and behavior while facing problems (Heppner, Witty, \& Dixon, 2004).

In general, problem solving ability helps to identify problems, find solutions, and cope with stressful everyday life situations through a cog- 
nitive, affective, and behavioral process (D'Zurilla, Maydeu-Olivares, \& Gallardo-Pujol, 2011). Additionally, many studies show that individuals having a positive appraisal of their problem solving ability are very likely to possess high problem solving skills (Heppner, Witty, \& Dixon, 2004). Individuals with positive problem solving self-appraisal have also higher expectations of success in problem solving; they solve problems more systematically, and are more persistent when solving problems (Heppner, 1988).

The research on problem solving appraisal reported that low perceived problem solving ability is associated with psychological maladjustment (D'Zurilla \& Goldfried, 1971; Heppner \& Krauskopf, 1987), low adaptation to stress (Heppner \& Baker, 1997), physical health problems (Heppner et al., 1987; Tracey et al., 1986) and perceived stress level, and most importantly, higher anxiety (Heppner, Kampa, \& Brunning, 1987; Larson et al., 1990; Nezu, 1985, 1986; Sahin, Sahin, \& Heppner, 1993; Tracey, Sherry, \& Keitel, 1986; Carscaddon, Poston, \& Sachs, 1988).

\section{Problem Solving Ability and Math Anxiety}

Although we already reported on several studies examining the relation between problem solving and math anxiety, these studies were mostly focused on mathematical task problem solving (Yeo, 2005; Karasel, Ayda, \& Tezer, 2010; Novak \& Tassel, 2017). Research examining the relationship of perceived problem solving ability, or systematic problem solving strategies and math anxiety is vastly missing in the literature. We found only two studies investigating this relationship (Akinsola, 2008; Murshidi, 1999). In the first study, Akinsola (2008) investigated math anxiety, math self-efficacy, locus of control, and study habits as predictors of perceived problem solving ability on a sample of in-service teachers. He found that these four constructs together contributed approx. $63 \%$ of the variance of perceived problem solving ability, while the math anxiety showed to be the strongest predictor. In the second study, Murshidi (1999) investigated the relationship between perceived problem solving ability (and its factors problem solving confidence, approach-avoidance style, and personal control) measured by PSI and math anxiety. The findings indicated a significant weak correlation between overall score in PSI and math anxiety. Moreover, the relationships between three problem solving sub-factors and math anxiety were significant but they were also weak, namely problem solving confidence ( $r=$ $.019)$, approach-avoidance style $(r=.07)$, and personal control $(r=.26)$. The strength of these relationships indicated that math anxiety was associated more with the emotional facets of problem solving, while it did not associate with behavioral consequences of avoiding or approaching the problem.

\section{Anxiety as a Personality Trait}

A very important and influential development in the research on anxiety can be attributed to Spielberger, Gorsuch, and Lushene (1970), who have made a distinction between trait and state anxiety. According to their definition, the "trait anxiety refers to relatively stable individual differences in anxiety proneness, that is, to differences between people in the tendency to respond to situations perceived as threatening..." (Spielberger, Gorsuch, \& Lushene, 1970, p. 2). High trait anxious individuals experience more frequent and more intensive anxiety compared to low trait anxiety individuals, but they are not anxious all the time. As Eysenck and Eysenck (1980) state, trait anxiety tends to moderate the level of state anxiety, which is triggered by situational demands. The State-Trait Anxiety Inventory (STAI; Spielberger, Gorsuch, \& Lushene, 1970) is one of the most widely used 
measures of state and trait anxiety. Since the main aim of this study is to examine the relationships between trait anxiety, perceived problem solving ability, and math anxiety, the following section is limited to and focused on investigating studies on the relation between trait anxiety and problem solving ability, as well as math anxiety.

\section{Trait Anxiety and Problem Solving Ability}

In their review, Heppner, Witty, and Dixon (2004) reported eight studies discovering a negative association between one's perceived problem solving ability and trait anxiety. However, they concluded that most of these studies were made on white U.S. college students, suggesting a need for further research in this area.

The strength of the association between perceived problem solving ability and trait anxiety differs in the research, although most studies report a moderate relationship (e.g., Sahin, Sahin, \& Heppner, 1993; Peng \& Huang, 2014; Heppner et al., 2002). Perhaps the strongest association was reported by Kant, D'Zurilla, and MaydeuOlivares (1997), who examined the relationship between trait anxiety and perceived problem solving ability using STAI and PSI measures. They found them to be negatively associated both in middle-aged and elderly samples (both correlations were $r=-.63$ ).

Although in general, problem solving ability significantly correlates with trait anxiety, research showed that different facets of problem solving ability differ in their relationship with trait anxiety. In their study, Davey et al. (1992) examined the relationships between trait anxiety and perceived problem solving ability measured by PSI. When examining the relationship between trait anxiety and individual factors of problem solving ability, they found trait anxiety to be significantly negatively correlated to problem solving confidence and personal control, with both of these relationships being moder- ate ( $r=.49$, and $r=.55$, respectively). The relationship between trait anxiety and approachavoidance style was not significant. Similarly, Heppner et al. (2002) examined three facets of PSI in relation to trait anxiety. They found a very similar relationships pattern as Davey et al. (1992) but the strengths were lower, namely a weak negative relationship between trait anxiety and perceived self-confidence $(r=.35)$, as well as personal control $(r=.34)$, and a nonsignificant relationship between trait anxiety and approach-avoidance style.

Another study, reporting similar findings about the relationship between trait anxiety and perceived problem solving ability measured by PSI, was proposed by Peng and Huang (2014). Like Heppner et al. (2002), they found a significant positive weak relationship between overall PSI score and trait anxiety $(r=.43)$. Moreover, the trait anxiety was related mostly to problem solving confidence and personal control dimensions ( $r=.46$, and $r=.44$, respectively), while the approach/avoidance style was very weakly related $(r=.24)$.

Belzer, D'Zurilla, and Olivares (2002) examined the relationships between trait anxiety, problem solving ability, and worry, using a Social Problem Solving Inventory-Revised (Maydeu-Olivares \& D'Zurilla, 1995) for measuring problem solving ability. They found that trait anxiety positively correlated with negative problem orientation $(r=.64)$, impulsivity in applying problem solving skills $(r=.23)$, and also avoidance style $(r=.37)$. Moreover, it negatively correlated with positive problem orientation $(r=-.43)$. These results suggest that individuals with high trait anxiety perceive problems as a threat and they tend to doubt their problem solving ability. Additionally, when solving a problem, they tend to be careless and impulsive, often procrastinate or wait for problems to resolve themselves, or shift the responsibility for problem solving to other individuals. 


\section{Trait Anxiety and Math Anxiety}

In the study of Betz (1978), math anxiety positively correlated with trait anxiety. Similarly, Hembree (1990) in his meta-analysis reported a positive weak relationship between math anxiety and trait anxiety $(r=.38)$. In a more recent study, Paechter et al. (2017) examined links between math anxiety, statistical anxiety and trait anxiety. They found that trait anxiety measured by STAI significantly predicted math anxiety. Trait anxiety together with grades in mathematics and gender explained approx. $37 \%$ of variance in math anxiety. When examining the relationship between trait anxiety and facets of math anxiety, Paechter et al. (2017) found a positive weak correlation with mathematics test anxiety $(r=.33)$, positive very weak correlation with mathematics course anxiety $(r=.18)$, and a non-significant relation with numerical task anxiety. Similarly to Paechter et al. (2017), McAuliffe and Trueblood (1986) also used STAI to measure trait anxiety and the Math Anxiety Rating Scale (MARS) to measure math anxiety. However, in this study, all three facets of math anxiety significantly positively correlated with trait anxiety, while all the relationships were weak, ranging from $r=.41$ to .44. In another study, Hopko, Mahadevan, Bare, and Hunt (2003) examined the relation between trait anxiety and math anxiety using two different measures of math anxiety (The Abbreviated Math Anxiety Scale - AMAS and Math Anxiety Rating Scale-Revised - MARSR). In both of these measures, the relationship with trait anxiety showed to be significant positive and weak, ranging from $r=.21$ to .28 . In addition to the above mentioned studies, reporting a positive association between trait anxiety and math anxiety, we found two studies which reported a non-significant relationship (Wu et al., 2012; Klados et al., 2015).

\section{The Aim of this Study}

In this study, we aim to investigate the relation between math anxiety, trait anxiety, and one's perceived problem solving ability. Although previous findings suggest that math anxiety, trait anxiety, and problem solving ability are closely linked to each other, from our analysis of literature, it seems that the relationships between these three constructs together have not been investigated yet. The following research questions are investigated:

- How does trait anxiety relate to the perceived problem solving ability, and mainly to personal self-confidence, approach-avoidance style, and personal control in problem solving?

- How does trait anxiety affect math anxiety?

- Does the perceived problem solving ability mediate the relation between trait anxiety and math anxiety?

To investigate the above research questions, we explore the relationship between trait anxiety and perceived problem solving ability, as well as its three facets. Moreover, we developed a mediation model of the relationship between trait anxiety, perceived problem solving and math anxiety.

Research on therelationship between trait anxiety and problem solving ability showed a negative association between these two constructs (Kant, D'Zurilla, \& Maydeu-Olivares, 1997; Sahin, Sahin, \& Heppner, 1993; Carscaddon, Poston \& Sachs, 1988; Daveyetal., 1992; Heppner et al., 2002). Moreover, it was found that trait anxiety relates mostly to perceived self-confidence and personal control in problem solving, while its relation with approach-avoidance style is weaker (Heppner et al., 2002; Davey et al., 1992; Peng \& Huang, 2014). According to these findings we assume that:

H1 Trait anxiety is a significant predictor of perceived problem solving ability. 
H2 There are negative moderate relationships of perceived-self-confidence and personal control facets with trait anxiety.

H3 There is a negative weak relationship between approach-avoidance style facet and trait anxiety.

Besides the negative relationship with perceived problem solving ability, the research on anxiety as a personality trait reported that this construct was positively related to math anxiety (Betz, 1978; Hembree, 1990; Paechter et al., 2017; McAuliffe \& Trueblood, 1986; Hopko, Mahadevan, Bare, \& Hunt, 2003). Moreover, research on math anxiety showed this construct to be negatively associated with problem solving ability (e.g., Yeo, 2005; Karasel, Ayda, \& Tezer, 2010; Novak \& Tassel, 2017). Most of these studies examined problem solving in mathematical tasks, where math anxiety acted as an independent predictor of this performance. However, as Ashcraft and Rudig (2012) stated, in the math anxiety research, very little is known about the causal mechanisms between the observed variables, i.e. we often do not know whether math anxiety causes a bad performance or math avoidance, or if it is the initially lower ability in mathematics that lead to lower math performance and subsequently to greater math anxiety. In the context of problem solving, this could mean that not just math anxiety affects the problem solving process, but also the ini- tially lower level of one's general problem solving abilities can lead to lower math performance and thus systematically promote the creation and occurrence of math anxiety. We found two studies reporting a negative relationship between problem solving ability self-appraisal and math anxiety (Murshidi, 1999; Akinsola, 2008). Moreover, there are some studies suggesting that problem solving ability predicts anxiety in general (Heppner, Witty, \& Dixon, 2004). According to these findings we assume that:

H4 Perceived problem solving ability will mediate the relationship between trait anxiety and math anxiety.

The mediation model of relationships between trait anxiety, perceived problem solving ability, and math anxiety is presented in Figure 1 .

\section{Method}

\section{Participants}

The participants in this study were 128 undergraduate university students (93 females) attending psychology $(n=49)$ and social work studies $(n=41)$ at the Constantine the Philosopher's University in Nitra, Slovakia, and economic disciplines $(n=38)$ at the Slovak University of Agriculture in Nitra, Slovakia. The age of participants ranged from 18 to 39 ( $A M=$

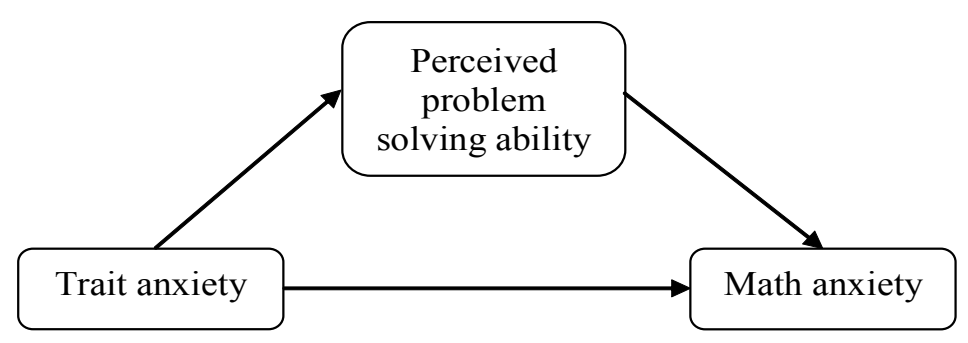

Figure 1 The mediation model 
21.92; $S D=3.72$ ). We used opportunity sampling, the participation was voluntary and no refusals were observed during data collecting. During their study, participants studying psychology and social work studies attended only few courses and lectures related to mathematics (only statistics). Participants studying economy had to use their mathematic skills in many lectures and courses during their study. They attended courses and lectures in mathematics, finance and currency, business economy, agriculture economics, statistics, basics of accounting, accounting for entrepreneurs, corporate finance, single entry accounting, costing and budgeting, financial and economic analysis.

\section{Procedure}

The data for this study was collected during a large group session after class periods. Before the data collection, participants were informed about the purpose of this study. Subsequently, they completed self-report measures in the following order: demographics, FSMAS$\mathrm{R}$, PSI, and STAI-X2. The data was collected using the pencil and paper method.

\section{Measures}

\section{Math Anxiety}

A revised version of the Fennema-Sherman Mathematics Anxiety Scale (FSMAS-R; Lim \& Chapman, 2013) was used for measuring math anxiety. This scale consists of nine items with a two-factor structure - FS-EASE and FS-ANX subscales. Both of these subscales measure math anxiety, but they differ in wording - the first is negatively worded and the latter is positively worded. Recent studies showed that these two subscales indicated two distinct dimensions, although it looks like they are just opposing indicators of the same dimension (see
Lim \& Chapman, 2013). The scale contains items like: "I usually don't worry about my ability to solve mathematics problems", or "My mind goes blank and I am unable to think clearly when working mathematics". In our study, the internal consistency of this scale was very high $(\alpha=$ $.904)$.

\section{Trait Anxiety}

We used the State/Trait Anxiety InventoryTrait Form (STAI-T; Spielberger, Gorsuch, \& Lushene, 1970) to measure trait anxiety. The Slovak version of this inventory was adapted by Müllner, Ruisel, and Farkaš (1980). The STAI-T consists of 20 items designed to measure an individual's longstanding proneness to anxiety, i.e. how individuals generally feel (anxiety as a personal trait). The inventory consists of items like: "I worry too much over something that really doesn't matter", or "I take disappointments so keenly that I can't put them out of my mind'. Very similar to the FSMAS-R in our study, the internal consistency of this scale was very high $(\alpha=.907)$.

\section{Perceived Problem Solving Ability}

A shortened Slovak version of The Problem Solving Inventory (PSI; Heppner \& Petersen, 1982) was used for measuring an individual's perceived problem solving ability. The original PSI is a 32-item self-report measure designed to assess individuals' perceptions of their problem solving ability and problem solving style. It consists of three factors: Problem Solving Confidence (PSC), Approach-Avoidance Style (AAS), and Personal Control (PC). The shortened Slovak version consists of 11 items (4 items for PSC and 4 items for AAS, and 3 items for PC). The scale contains items like: "Given enough time and effort, I believe I can solve most problems that confront me (PSC)", or "When I have a problem, I think up as many 
possible ways to handle it as I can until I can't come up with any more ideas (AAS)". The previous confirmatory factor analysis showed a good model fit for the three-dimensional structure for this shortened version (Grežo \& Sarmány-Schuller, 2018). The reliability test showed an acceptable internal consistency $(\alpha=.728)$.

\section{Data Analysis}

The data was analyzed using SPSS software. Descriptive statistics were used to explore demographic characteristics of the research sample. Before examining the relationships between observed variables, we investigated whether our research samples differed significantly in these variables according to the field of study (psychology, social work, and economy). Since we did not find any significant differences in math anxiety, trait anxiety, or perceived problem solving ability in these three groups, we merged all participants into one group and conducted further analyses without regard to the field of study. Correlations of math anxiety, trait anxiety, and perceived problem solving ability were analyzed using Pearson's correlation test. Finally, the mediating effect of perceived problem solving ability on the relationship between trait anxiety and math anxiety was tested using Hayes' PROCESS macro for SPSS (see Hayes, 2013).

\section{Results}

\section{Descriptive Statistics}

Table 1 provides means and standard deviations for each measure used in this study and it also reports correlations between the observed variables. The level of all three main variables as well as their variances showed to be very similar compared to the values reported in previous studies (e.g., Paechter et al., 2017;

Table 1 Descriptive statistics and correlations of study measures

\begin{tabular}{|c|c|c|c|c|c|c|}
\hline & PSI_OVRL & PSI_PSC & PSI_AAS & PSI_PS & MA & STAI \\
\hline PSI_OVRL & 1 & & & & & \\
\hline PSI_PSC & $.767 * *$ & 1 & & & & \\
\hline PSI_AAS & $.576 * *$ & .061 & 1 & & & \\
\hline PSI_PS & $.806^{* *}$ & $.615 * *$ & .133 & 1 & & \\
\hline MA & -.013 & -.009 & .053 & -.077 & 1 & \\
\hline STAI & $-.473 * *$ & $-.574 * *$ & .034 & $-.497 * *$ & -.090 & 1 \\
\hline AM & 24.693 & 9.272 & 8.702 & 6.719 & 27.781 & 43.807 \\
\hline $\mathrm{SD}$ & 4.137 & 1.873 & 2.013 & 1.916 & 8.786 & 9.316 \\
\hline Variance & 17.117 & 3.509 & 4.052 & 3.673 & 77.199 & 86.794 \\
\hline Min & 14 & 5 & 4 & 3 & 9 & 23 \\
\hline Max & 34 & 13 & 15 & 11 & 43 & 69 \\
\hline
\end{tabular}

Note. PSI_OVRL - Problem Solving Inventory overall score; PSI_PSC - Problem Solving Inventory personal control score; PSI_AAS - Problem Solving Inventory approachavoidance score; PSI_PS - Problem Solving Inventory personal control score; MA - Math anxiety FSMAS-R score; STAI - State Trait Anxiety Inventory - Trait form score. Gender is partialled out of all correlations. $* * \mathrm{p}<.01$ 
Heppner et al., 2002; Kourmousi, Xythali, Theologitou, \& Koutras, 2016; Yeo, 2005; Peng, 2014), suggesting that, in general, our research sample exhibited normal and average values in math anxiety, trait anxiety and also perceived problem solving ability. In order to interpret the level of perceived problem solving ability, trait anxiety, and math anxiety of the research sample, it is helpful to analyze mean scores of variables. Table 1 indicates that mean scores of perceived problem solving ability and trait anxiety were under the midrange values (2.81 and 6.19 points, respectively), while mean score of math anxiety was only slightly above the mid-range value $(0.78$ points) of the self-report scales used. Since some of the previous studies found significant gender differences in the perceived problem solving ability, trait anxiety, and also math anxiety, a series of independent sample $t$-tests were conducted with gender as a betweengroup variable for these measures. We did not find significant differences between men and women in PSI scores (overall, or any of the factors score), and trait anxiety. However, women reported significantly higher math anxiety overall score, and also both math anxiety factor scores compared to men. Therefore, we controlled for gender in all further analyses which included math anxiety scores.

\section{Trait Anxiety as a Predictor of Perceived Problem Solving Ability}

In order to examine whether trait anxiety predicts overall score and also scores of three factors of the perceived problem solving ability, simple linear regressions were performed. For each analysis, the trait anxiety score was entered as an independent variable. The first linear regression analysis showed that trait anxiety accounted for $22.5 \%$ of the variance in the perceived problem solving ability. The relationship between trait anxiety and perceived problem solving ability showed to be weak and negative (Table 2). When investigating the effect of trait anxiety on the three facets of the Problem Solving Inventory, we found that trait anxiety significantly predicted perceived self-confidence and personal control, explaining 33.2\% and $24.7 \%$ of their variance, respectively. Analyses also showed that the relationships between the observed variables were negative and moderate, suggesting that the more anxiety one possesses, the lower perceived problem solving ability s/he has, and specifically, the lower self-confidence and personal control of emotions and behavior one experiences during problem solving. Finally, it was shown that trait anxiety did not significantly predict the approach-

Table 2 Linear regressions showing the amount of variance in perceived problem solving ability explained by trait anxiety

\begin{tabular}{lccccc}
\hline & $\beta$ & $\mathrm{R}$ & $\mathrm{R}^{2}$ & d.f. & $\mathrm{F}$ \\
\hline PSI_OVRL & .210 & .473 & .225 & 113 & $32.444^{* *}$ \\
PSI_PSC & .116 & .576 & .332 & 113 & $55.757^{* *}$ \\
PSI_AAS & -.008 & .034 & .001 & 113 & .143 \\
PSI_PC & .102 & .497 & .247 & 113 & $36.752^{* *}$ \\
\hline
\end{tabular}

Note. PSI_OVRL - Problem Solving Inventory overall score; PSI PSC - Problem Solving Inventory personal control score; PSI_AAS - Problem Solving Inventory approach-avoidance score; PSI_PS - Problem Solving Inventory personal control score. $* * \mathrm{p}<.001$ 
avoidance factor score, suggesting that trait anxiety does not affect whether one tends to avoid or approach problems (Table 2).

\section{Perceived Problem Solving Ability as a Me- diator of the Relationship between Trait Anxi- ety and Math Anxiety}

In order to test the mediation effect of the perceived problem solving ability on the relationship between trait anxiety and math anxiety, a three-step regression analysis method was used (Baron \& Kenny, 1986). In this method, three criteria have to be fulfilled to support the mediation model: 1) the independent variable must be a significant predictor of the mediator; 2) the independent variable must be a significant predictor of the dependent variable; and 3) the mediator must be a significant predictor of the dependent variable while the effect of the independent variable on the dependent variable must be lower than it was in the second step (Baron \& Kenny, 1986). The results of the threestep regression analysis are reported in Figure 2. In the first step (path a), the trait anxiety showed to be a significant predictor of the perceived problem solving ability $(b=.211 ; t(112)$ $=5.696 ; p<.01$. In the second step (path $\mathrm{c}$,
Figure 2), the trait anxiety did not significantly predict math anxiety $(b=-.059 ; t(112)=-.668$; $p=.505$ ). Finally, in the third step (path $\mathrm{b}$ ), the perceived problem solving ability did not significantly predict math anxiety $(b=.069 ; t(111)$ $=.304 ; p<.762)$. Moreover, in this step, the effect of trait anxiety was strengthened compared to the effect that was reported in the second analysis. Since the criteria of second and third step were violated, the mediation model was not supported and the perceived problem solving ability did not show to be a significant mediator of the relationship between trait anxiety and math anxiety. Moreover, it was found that not even trait anxiety significantly predicted math anxiety.

\section{Discussion}

The Relationship between Perceived Problem Solving Ability and Trait Anxiety

The results of this study support our hypothesis about the negative relationship between trait anxiety and perceived problem solving ability. Similar to most of the previous studies (Sahin, Sahin, \& Heppner, 1993; Peng \& Huang, 2014; Heppner et al., 2002), we found a moder-

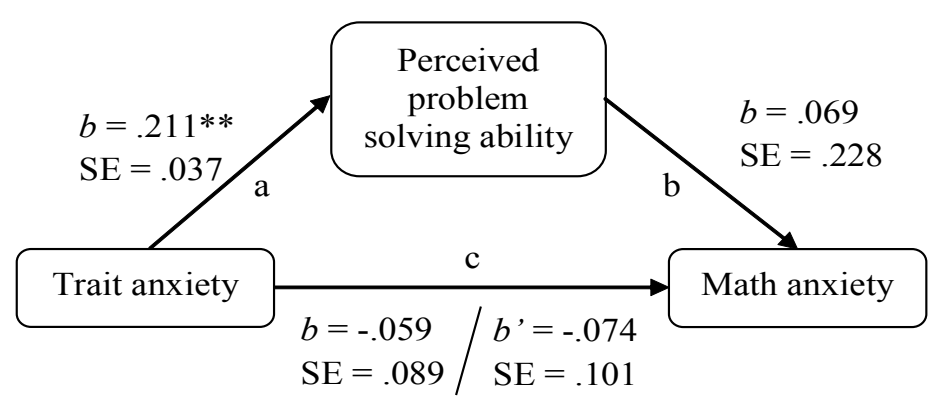

Note. Figure shows unstandardized OLS regression coefficients; $* * p<.01$.

Figure 2 Results of the mediation analysis 
ate negative relationship between the overall perceived problem solving ability and trait anxiety. Additionally, we found that trait anxiety was negatively associated with perceived self-confidence and personal control factors of the perceived problem solving ability. This result supports our second hypothesis and it is also comparable with previous studies. Compared to our study, the most similar results about the relationship between trait anxiety and perceived problem solving ability factors were reported by Davey et al. (1992). They also found perceived self-confidence and personal control to be moderately related to trait anxiety and the strength of the relations was very similar to ours. In the study of Peng and Huang (2014), trait anxiety was also moderately associated with both perceived self-confidence and personal control, although the strength of associations was lower, compared to our results. However, our results do not support the third hypothesis about the weak association between approachavoidance style facet and trait anxiety. In the study of Peng and Huang (2014), the relationship between trait anxiety and approach-avoidance style was found to be significant and weak. Similar significant weak association was reported by Heppner et al. (2002). Our results are consistent with those of Davey et al. (1992), who did not find a significant relationship between trait anxiety and approach-avoidance style. This inconsistency in the results concerning the relationship between trait anxiety and approach-avoidance style highlights the importance of further investigation of this area. In the previous research, perceived self-confidence and personal control factors of the shortened Slovak PSI version were strongly associated (Grežo \& Sarmány-Schuller, 2018). In general, items in these two factors are more about one's emotional experiencing (e.g.: “...I make snap judgments and later regret them; ...I become uneasy about my ability...; ...I am unsure whether I can handle the situation"), while the approach-avoidance style is more about one's cognition and process of solving the problem (e.g., "After I have solved a problem, I do not analyze what went right or what went wrong; I generally go with the first good idea...; When I have a problem, I think up as many possible ways to handle it as I can..."). This overlap between perceived self-confidence and personal control, together with our results, could suggest that anxiety as a personality trait is mostly associated with the affective aspect of problem solving, i.e. the experiencing of doubts, uncertainty about one's own abilities, feelings of worry, fear, or regret about the results of problem solving.

\section{The Independence of Math Anxiety}

We assumed that the perceived problem solving ability would mediate the relationship between trait anxiety and math anxiety. However, the results of mediation analysis do not support this hypothesis. Although we found a significant effect of trait anxiety on the perceived problem solving ability, the effects of trait anxiety and also perceived problem solving ability on math anxiety were not significant. This result suggests that trait anxiety does not directly affect the amount of negative feelings experienced during math related tasks and situations, nor does trait anxiety lead to lower perceived problem solving ability, which in turn results in higher levels of math anxiety. Perhaps the most unexpected result of this study was that trait anxiety did not significantly correlate with math anxiety. This result is not in line with the majority of previous studies investigating this relationship (Betz, 1978; Hembree, 1990; Paechter, 2017; McAuliffe \& Trueblood, 1986; Hopko, Mahadevan, Bare, \& Hunt, 2003). We found two studies which did not find a significant relationship between trait anxiety and math anxiety but these studies differed from those reported above (Wu et al., 2012; Klados et al., 2015). In 
the first study of Klados et al. (2015), the research sample consisted of a very small number of participants, which could affect the significance level of correlation between trait anxiety and math anxiety. In the second study, Wu et al. (2012) used their own method for measuring math anxiety. This method was created on the basis of the widely used MARS and MARSE measures, but it was adapted for children who were in the early stages of math learning. To be able to compare the results from this modified method and other widely used measures (e.g., AMAS, MARS), it would require an initial testing whether/to what extent these different measures correlate and how they differ in their internal structures. Moreover, for measuring trait anxiety, Wu et al. (2012) did not use any of the widely used measures (e.g., STAI), but only an Anxiety Problems subscale of Child Behavior Checklist (Achenbach, 1991). This could be insufficient, since in this scale anxiety and depression items are not separated and are perceived as a part of the same continuum of problems (Wadsworth, Hudziak, Heath, \& Achenbach, 2001).

\section{Explaining a Non-Significant Relationship between Math Anxiety and Trait Anxiety}

Although our mediation model was not supported, our results suggest that trait anxiety and math anxiety are clearly distinct and different constructs. When interpreting a non-significant relationship between math anxiety and trait anxiety, we checked for the level and variability of our variables and compared them with previous studies. However, we did not find any significant differences between our sample and the samples of other studies. The mean score and variability of trait anxiety differed negligibly, compared to studies of Paechter et al. (2017), Heppner et al. (2002) and Yeo (2005). We also did not find any significant differences in mean scores and variability of perceived problem solv- ing and math anxiety, compared to previous studies (Kourmousi, Xythali, Theologitou, \& Koutras, 2016; Heppner et al., 2002; Yeo, 2005; Peng, 2014; Novak \& Tassel, 2017).

Although the level and variability of our variables did not explain a non-significant effect of trait anxiety on math anxiety in our study, there were several important differences between our and previous studies that could be important. Compared to trait anxiety, math anxiety seems to be a more complex construct that is affected by many different factors. These factors could be not just personality traits (e.g., trait anxiety) but also environmental and contextual factors. As Akinsola (2008) stated, they can be divided into three areas: environmental, intellectual, and personality factors. Environmental factors include parental pressure, insensitive teacher, non-participatory classrooms, and negative experiences with mathematics in the classroom. Intellectual factors include student attitudes toward mathematics, self-doubt and lack of confidence in one's abilities, and lack of perceived usefulness of mathematics. Finally, personality factors include reluctance to ask questions due to shyness, low self-esteem, or viewing mathematics as a male domain (Akinsola, 2008). Moreover, very important aspects affecting math anxiety include exposure to people's negative attitudes toward mathematics, experiencing failures or the threat of mathematics (Dowker, Sarkar, \& Looi, 2016). Taking this into account, a very important aspect could be that our participants were university students of humanities. The majority of our sample were students of psychology and social work, who do not attend any math courses and they are not in contact with mathematics to a great extent. During their studies, they face math-related situations or tasks very rarely, therefore do not experience any failures or threat of mathematics. Moreover, their study success and selfimage does not depend on their math ability. Another important aspect could be the age of 
an individual. The majority of studies on math anxiety were conducted on primary and secondary school students. As Dowker, Sarkar, and Looi (2016) pointed out, during this period math anxiety is deteriorating and mostly escalating during adolescence. This can be caused by both greater demands for mathematics abilities (math is getting harder) and more sensitivity to anxiety in general in adolescence. Even though individuals in our study might experience various types of anxieties during their study, compared to the primary and secondary school-aged students they could not experience math anxiety in such great extent. This could lead to the importance of investigating the role of age in math anxiety, i.e. how math anxiety differs as a function of age and whether the relationship between trait anxiety and math anxiety differs across different age categories. Since there is an absence of studies on math anxiety conducted on middle-aged or older adults, we emphasize the need for conducting such research. Additionally, we can assume that the important aspect of the relationship between trait anxiety and math anxiety could be the amount of mathrelated situations and tasks one is exposed to. Since most of the studies investigate math anxiety on primary and secondary school students who study mathematics, very little is known whether math anxiety tends to disappear when these individuals no longer study math and are no longer exposed to math-related situations (e.g., math courses, doing math in front of classmates, math tests, math-related careers), i.e. they do not experience state math anxiety. The importance of properly distinguishing between math anxiety, as a relatively stable personality trait and as a current state that is more dependent on contextual and environmental factors, was already highlighted in a recent study of Roos et al. (2015). Translating our assumption into this context, the trait math anxiety could determine the amount of experienced state math anxiety, but also, the higher/lower number of math-anxious states or situations one experiences could foster/suppress the amount of one's trait math anxiety. However, since the issue of causality pointed out by Ashcraft and Rudig (2012) significantly limits the research on math anxiety, it could be difficult to investigate this assumption.

\section{Study Limitations and Directions for Future Research}

Despite this negative effect of trait anxiety on emotional experiencing during problem solving, our results also suggest that trait anxiety does not affect how an individual tackles the problem and what strategies s/he is using in the process of problem solving. Although higher trait anxious individuals experience more doubts, worry or fear about their abilities or the result of problem solving, they do not tend to avoid solving the problem, they search for various alternative solutions, and also monitor whether the solution was correct, similarly to lower trait anxious individuals. However, as we stated before, some studies found a significant association between trait anxiety and approachavoidance factor of the perceived problem solving ability (Peng \& Huang, 2014; Heppner et al., 2002). Therefore, we highlight the importance of further investigation of these two constructs. We propose examining individual differences in other related constructs, such as approachavoidance coping strategies (Roth \& Cohen, 1986), which could further explain the relation between trait anxiety and approach-avoidance problem solving style. Additionally, using real problem solving tasks, and not just self-report scales, could help to understand the effect of trait anxiety on one's approach-avoidance tendencies. In this study, and also in the above discussed studies on the perceived problem solving ability (Sahin, Sahin, \& Heppner, 1993; Peng \& Huang, 2014; Heppner et al., 2002; Davey et al., 1992), this aspect is missing. Butler and 
Meichenbaum (1981) argue that one's self-perception of his/her own problem solving abilities strongly affect not just the real objective problem solving performance, but also the process of solving a problem. We highlight the importance of distinguishing and using both objective problem solving abilities, measured in problem solving performance tasks, and perceived problem solving ability based on a selfreport scales in the future research.

Another missing aspect in this study is the deeper observation of the amount of math experience participants had and how many math related situations they encounter in their everyday life. Since our study sample consisted of university students, we possessed only information about what math related courses they attended during their study. Although our samples (psychology, sociology, and economy) differed significantly in the amount of attended courses related to math, they did not significantly differ in math anxiety score. However, as we stated before, math anxiety can be experienced not just during math courses or lectures, but also in math related everyday situations such as reading a cash register receipt (Richardson \& Suinn, 1972; Buckley \& Ribordy, 1982). A deeper observation of one's behavior in everyday math related situations as well as the frequency and intensity of threatening math situations an individual faces in his/her everyday life could further explain the inconsistent findings about the relationship between math anxiety and trait anxiety.

\section{References}

Achenbach, T. M. (1991). Manual for the Child Behavior Checklist / 4-18 and 1991 Profile. Burlington, VT: University of Vermont.

Akinsola, M. K. (2008). Relationship of some psychological variables in predicting problem solving ability of in-service mathematics teachers, The Mathematics Enthusiast, 5(1), 79-100.

Ashcraft, M. H. (1992). Cognitive arithmetic: A review of data and theory. Cognition, 44, 75-106.
Ashcraft, M. H. (2002). Math anxiety: Personal, educational, and cognitive consequences. Current Directions in Psychological Science, 11(5), 181-185.

Ashcraft, M. H., \& Kirk, E. P. (2001). The relationships among working memory, math anxiety, and performance. Journal of Experimental Psychology: General, 130(2), 224-237.

Ashcraft, M. H., \& Krause, J. A. (2007). Working memory, math performance, and math anxiety. Psychonomic Bulletin \& Review, 14(2), 243-248.

Ashcraft, M. H., Kirk, E. P., \& Hopko, D. (1998). On the cognitive consequences of mathematics anxiety. In C. Donlan (Ed.), The Development of Mathematical Skills (pp. 175-196). Hove: Erlbaum.

Ashcraft, M. H., \& Moore, A. M. (2009). Mathematics anxiety and the affective drop in performance. Journal of Psychoeducational Assessment, 27(3), 197-205.

Ashcraft, M. H., \& Ridley, K. S. (2005). Math anxiety and its cognitive consequences: A tutorial review. In J. I. D. Campbell (Ed.), The Handbook of Mathematical Cognition (pp. 315-327). New York: Psychology Press.

Ashcraft, M. H., \& Rudig, N. O. (2012). Higher cognition is altered by noncognitive factors: How affect enhances and disrupts mathematics performance in adolescence and young adulthood. In V. F. Reyna, S. B. Chapman, M. R. Dougherty, \& J. Confrey (Eds.), The Adolescent Brain: Learning, Reasoning, and Decision Making (pp. 243-263). Washington, DC: APA.

Baron, R. M., \& Kenny, D. A. (1986). The moderatormediator variable distinction in social psychological research: Conceptual, strategic, and statistical considerations. Journal of Personality and Social Psychology, 51, 1173-1182.

Belzer, K. D., D’Zurilla, T. J., \& Maydeu-Olivares, A. (2002). Social problem solving and trait anxiety as predictors of worry in a college student population. Personality and Individual Differences, 33, 573585 .

Betz, N. E. (1978). Prevalence, distribution, and correlates of math anxiety in college students. Journal of Counseling Psychology, 25(5), 441-448.

Buckley, P. A., \& Ribordy, S. C. (1982). Mathematics anxiety and the effects of evaluative instructions on math performance. Paper presented at the Midwestern Psychological Association, Minneapolis, MN, May 6-8.

Butler, L., \& Meichenbaum, D. (1981). The assessment of interpersonal problem-solving skills. In P. C. Kendall, \& S. D. Hollon (Eds.), Assessment Strategies for Cognitive-Behavioral Interventions (pp. 197-225). New York: Academic Press.

Carscaddon, D. M., Poston, J., \& Sachs, E. (1988). Problem-solving appraisal as it relates to state-trait 
personality factors. A Journal of Human Behavior, $25,73-76$

Covington, M. V. (1992). Making the grade. A selfworth perspective on motivation and school reform. New York: Cambridge University Press.

Davey, G. C., Hampton, J., Farrell, J., \& Davidson, S. (1992). Some characteristics of worrying: Evidence for worrying and anxiety as separate constructs. Personality and Individual Differences, 13, 133147.

Dew, K., Galassi, J., \& Galassi, M. (1983). Mathematics anxiety: Some basic issues. Journal of Counseling Psychology, 30, 443-446.

Dogan, H. (2010). Emotion, confidence, perception and expectation. Case of mathematics. International Journal of Science and Mathematics Education, 10(1), 49-69.

Dowker, A. D. (2005). Individual differences in arithmetic: Implications for psychology neuroscience and education. Hove: Psychology Press.

Dowker, A., Sarkar, A., \& Looi, C. Y. (2016). Mathematics anxiety: What have we learned in 60 years? Frontiers in Psychology, 7:508.

D'Zurilla, T. J., \& Goldfried, M. R. (1971). Problem solving and behavior modification. Journal of $\mathrm{Ab}$ normal Psychology, 78, 107-126.

D’Zurilla, T. J., \& Nezu, A. M. (2007). Problem-solving therapy: A positive approach to clinical intervention (3rd ed.). New York: Spring Publishing Company.

D'Zurilla, T. J., Maydeu-Olivares, A., \& Gallardo-Pujol, D. (2011). Predicting social problem solving using personality traits. Personality and Individual Differences, 50, 142-147.

Eysenck, M. W., \& Eysenck, H. J. (1980). Mischel and the concept of personality. British Journal of Psychology, 71, 191-204.

Faust, M. W. (1992). Analysis of physiological reactivity in mathematics anxiety. Unpublished doctora dissertation, Bowling Green State University, Bowling Green, Ohio.

Fennema, E., \& Sherman, J. A. (1976). FennemaSherman mathematics attitudes scales: Instruments designed to measure attitudes towards the learning of mathematics by females and males. Journal for Research in Mathematics Education, 7(5), 324326.

Fürst, A., \& Hitch, G. J. (2000). Separate roles for executive and phonological components of working memory in mental arithmetic. Memory and Cognition, 28(5), 774-782.

Ganley, C. M., \& Vasilyeva, M. (2014). The role of anxiety and working memory in gender differences in mathematics. Journal of Educational Psychology, 106(1), 105-120.
Grežo, M., \& Sarmány-Schuller, I. (2018). Faktorová analýza skrátenej verzie inventára na sebaposudzovanie schopnosti riešit' problémy. In I. SarmánySchuller (Ed.), Agresia vo verejnom priestore: 35. Psychologické dni. Zbornik príspevkov (pp. 63-79). Bratislava: SPS pri SAV.

Hayes, A. F. (2013). Methodology in the social sciences. Introduction to mediation, moderation, and conditional process analysis: A regression-based approach. New York, US: Guilford Press.

Hembree, R. (1990). The nature, effects and relief of mathematics anxiety. Journal for Research in Mathematics Education, 21(1), 33-46.

Heppner, P. P., \& Baker, C. E. (1997). Applications of the Problem Solving Inventory. Measurement and Evaluation in Counseling and Development, 29, 229-241.

Heppner, P. P., Kampa, M., \& Brunning, L. (1987). The relationship between problem solving self-appraisal and indices of physical and psychological health. Cognitive Therapy and Research, 11, 155168.

Heppner, P. P., \& Krauskopf, C. J. (1987). An information-processing approach to personal problem solving. The Counseling Psychologist, 15, 371-447.

Heppner, P. P., \& Petersen, C. H. (1982). The development and implications of a personal problemsolving inventory. Journal of Counseling Psychology, 29, 66-75.

Heppner, P. P., Pretorius, T. B., Wei, M., Lee, D., \& Wang, Y. (2002). Examining the generalizability of problem-solving appraisal in Black South Africans. Journal of Counseling Psychology, 49, 484-498.

Heppner, P. P., Witty, T. E., \& Dixon, W. A. (2004). Problem-solving appraisal and human adjustment: A review of 20 years of research using the Problem Solving Inventory. The Counseling Psychologist, $32(3), 344-428$.

Hitch, G. (1978). The role of short-term working memory in mental arithmetic. Cognitive Psychology, $10(3), 302-310$.

Hopko, D. R., Mahadevan, R., Bare, R. L., \& Hunt, M. K. (2003). The Abbreviated Math Anxiety Scale (AMAS): Construction, validity, and reliability. Assessment, 10(2), 178-182.

Kant, G. L., D’Zurilla, T. J., \& Maydeu-Olivares, A. (1997). Social problem solving as a mediator of stressrelated depression and anxiety in middle-aged and elderly community residents. Cognitive Therapy and Research, 21, 73-96.

Karasel, N., Ayda, O., \& Tezer, M. (2010). The relationship between mathematics anxiety and mathematical problem solving skills among primary school students. Procedia Social and Behavioral Sciences, 2, 5804-5808. 
Klados, M. A., Simos, P., Micheloyannis, S., Margulies, D. \& Bamidis, P. D. (2015). ERP measures of math anxiety: How math anxiety affects working memory and mental calculation tasks? Frontiers in Behavioral Neuroscience, 9:282.

Kourmousi, N., Xythali, V., Theologitou, M., \& Koutras, V. (2016). Validity and reliability of the Problem Solving Inventory (PSI) in a nationwide sample of Greek educators. Social Sciences, 5(25), $1-11$.

Larson, L. M., Piersel, W. C., Imao, R. A., \& Allen, S. J. (1990). Significant predictors of problem-solving appraisal. Journal of Counseling Psychology, 37, 482-490.

Lim, S. Y., \& Chapman, E. (2013). An investigation of the Fennema-Sherman Mathematics Anxiety Subscale. Measurement and Evaluation in Counselling and Development, 46(1), 26-37.

Yeo, K. K. (2005). Anxiety and performance on mathematical problem solving of Secondary Two students in Singapore. The Mathematics Educator, 8(2), 7183.

Ma, X. (1999). A meta-analysis of the relationship between anxiety toward mathematics and achievement in mathematics. Journal for Research in Mathematics Education, 30, 520-540.

Maloney, E. A., \& Beilock, S. L. (2012). Math anxiety: Who has it, why it develops, and how to guard against it. Trends in Cognitive Sciences, 16, 404-406.

Mattarella-Micke, A., Mateo, J., Kozak, M. N., Foster, K., \& Beilock, S. (2011). Choke or thrive? The relation between salivary cortisol and math performance depends on individual differences in working memory and math-anxiety. Emotion, 11(4), 10001005 .

Maydeu-Olivares, A., \& D’Zurilla, T. J. (1995). A factor analysis of the Social Problem Solving Inventory using polychoric correlations. European Journal of Psychological Assessment, 11, 98-107.

McAuliffe, E. A., \& Trueblood, C. R. (1986). Factor analysis: A tool for studying mathematics anxiety. Paper presented at the Annual Meeting of the American Educational Research Association, San Francisco, USA.

Miller, H., \& Bichsel, J. (2004). Anxiety, working memory, gender, and math performance. Personality and Individual Differences, 37, 591-606.

Murshidi, R. (1999). Relationship between problem solving styles and mathematics anxiety among Form Four science students. Unpublished master's thesis, Universiti Malaysia Sarawak.

Müllner, J., Ruisel, I., \& Farkaš, G. (1980). Príručka pre administráciu, interpretáciu a vyhodnocovanie dotaznika na meranie úzkosti a úzkostlivosti. Bratislava: Psychodiagnostické a didaktické testy.
Nezu, A. M. (1985). Differences in psychological distress between effective and ineffective problem solvers. Journal of Counseling Psychology, 32, 135138 .

Nezu, A. M. (1986). Negative life stress and anxiety: Problem solving as a moderator variable. Psychological Reports, 58, 279-283.

Novak, E., \& Tassell, J. L. (2017). Studying preservice teacher math anxiety and mathematics performance in geometry, word, and non-word problem solving. Learning and Individual Differences, 54, 20-29.

Onwuegbuzie, A. J. \& Wilson, V. A. (2003). Statistics anxiety: Nature, etiology, antecedents, effects, and treatments - A comprehensive review of the literature. Teaching in Higher Education, 8(2), 195209.

Paechter, M., Macher, D., Martskvishvili, K., Wimmer, S., \& Papousek, I. (2017). Mathematics anxiety and statistics anxiety. Shared but also unshared components and antagonistic contributions to performance in statistics. Frontiers in Psychology, 8:1196.

Peng, H., \& Huang, T. C. (2014). An examination of college students' state anxiety to trait anxiety, problem solving status and spirituality. International Journal of Academic Research and Reflection, 2(4), 6480 .

Pletzer, B., Wood, G., Moeller, K., Nuerk, H. C., \& Kerschbaum, H. H. (2010). Predictors of performance in a real-life statistics examination depend on the individual cortisol profile. Biological Psychology, 85(3), 410-416.

Punaro, L., \& Reeve, R. (2012). Relationships between 9-year-old's math and literacy worries and academic abilities. Child Development Research, 2012, 1-11.

Ramirez, G., Chang, H., Maloney, E. A., Levine, S. C., \& Beilock, S. L. (2016). On the relationship between math anxiety and math achievement in early elementary school: The role of problem solving strategies. Journal of Experimental Child Psychology, 141,83-100.

Richardson, F. C., \& Suinn, R. M. (1972). The Mathematics Anxiety Rating Scale. Journal of Counselling Psychology, 19(6), 551-554.

Roos, A. L., Bieg, M., Goetz, T., Frenzel, A. C., Taxer, J., \& Zeidner, M. (2015). Experiencing more mathematics anxiety than expected? Contrasting trait and state anxiety in high achieving students. High Ability Studies, 26(2), 245-258.

Roth, S., \& Cohen, L. J. (1986). Approach, avoidance, and coping with stress. American Psychologist, 41(7), 813-819.

Şad, S. N., Kış, A., Demir, M., \& Özer, N. (2016). Meta-analysis of the relationship between mathematics anxiety and mathematics achievement. Pegem Ĕgitim ve Ögretim Dergisi, 6(3), 371-392. 
Sahin, N., Sahin, N. H., \& Heppner, P. P. (1993). Psychometric properties of the Problem Solving Inventory in a group of Turkish university students. Cognitive Therapy and Research, 17, 379-396.

Spielberger, C. D., Gorsuch, R. L., \& Lushene, R. E. (1970). Manual for the State-Trait Anxiety Inventory. Palo Alto, CA: Consulting Psychologists Press

Tracey, T. J., Sherry, P., \& Keitel, M. (1986). Distress and help-seeking as a function of person environment fit and self-efficacy: A causal model. American Journal of Community Psychology, 14, 657-676.

Turner, J. C., Midgley, C., Meyer, D. K., Gheen, M. Anderman, E. M., Kang, Y., \& Patrick, H. (2002). The classroom environment and students' reports of avoidance strategies in mathematics: A multimethod study. Journal of Educational Psychology, 94, 88-106.

Wadsworth, M. E., Hudziak, J. J., Heath, A. C., \& Achenbach, T. M. (2001). Latent class analysis of child behavior checklist anxiety/depression in chil- dren and adolescents. Journal of the American Academy of Child \& Adolescence Psychiatry. 40(1), 106114.

Wigfield, A., \& Meece, J. L. (1988). Math anxiety in elementary and secondary school students. Journal of Educational Psychology, 80(2), 210-216.

Wilt, J., Oehlberg, K., \& Revelle, W. (2011). Anxiety in personality. Personality and Individual Differences, 50(7), 987-993.

Wu, S. S., Barth, M., Amin, H., Malcarne, V., \& Menon, V. (2012). Math anxiety in second and third graders and its relation to mathematics achievement. Frontiers in Psychology, 3:162.

Zakaria, E., \& Nordin, N. M. (2008). The effects of math anxiety on matriculation students as related to motivation and achievement. Eurasia Journal of Mathematics, Science \& Technology Education, 4, 27-30.

Zeidner, M. (1998). Test anxiety: The state of the art. New York, NY: Plenum. 